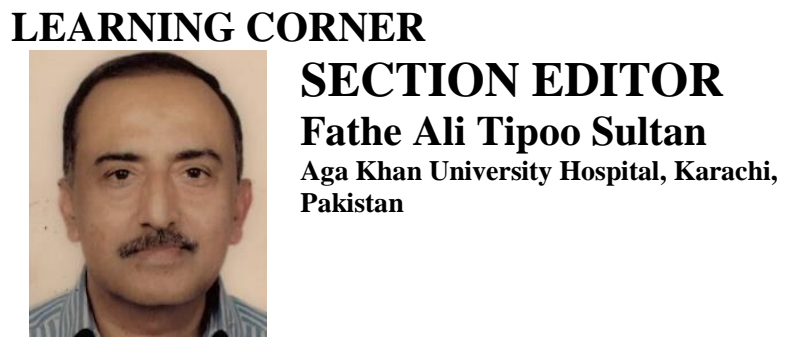

Dr. Tipoo is currently working as Associate Professor and Consultant Cardiologist at Aga Khan University Hospital, Karachi. Dr. Tipoo has 46 publications in Indexed National and International Journals and is the author of a book on Echocardiography.

\title{
PULMONARY ARTERY ANEURYSM- IDIOPATHIC
}

\author{
Imran Hameed ${ }^{1}$ \\ ${ }^{1}$ Anklesaria Nursing Home, Karachi, Pakistan
}

SUMMARY

A 28-years old female presented with complaints of palpitations and mild retrosternal chest pain. CXR showed a prominent Pulmonary artery. A TTE study revealed a huge main pulmonary artery whereas the branches were of normal size. CT angio revealed aneurysmal main Pulmonary artery and normal sized branches. No concomitant etiology was noted, hence labelled as "idiopathic pulmonary artery aneurysm".

\section{CASE DESCRIPTION}

A 28-year-old female presented with retrosternal chest pain and palpitations for the last six months. Multiple systolic clicks and murmur III/VI heard in the pulmonary area. ECG was unremarkable. Chest X-Ray showed no cardiomegaly and a prominent pulmonary artery. Transthoracic echocardiography showed aneurysmally dilated main pulmonary artery (size: $5.7 \mathrm{~cm}$ ). Pulmonary valve was thickened with mild regurgitation. CT angiogram demonstrated dilated main pulmonary artery (axial dimension: $5.8 \mathrm{~cm}$ ) with normal-sized branches (Figure1). Immunological workup was negative. She was advised surgical intervention which she agreed to pursue soon at a tertiary care hospital near her hometown.

\section{LEARNING POINTS}

1. Pulmonary artery aneurysm has an incidence of 1 in 14,000, (based on 109,571 autopsies). ${ }^{1}$

2. The maximum normal diameter of MPA is $29 \mathrm{~mm}$ in males and $27 \mathrm{~mm}$ in females. For interlobar branches the maximum size it 17 $\mathrm{mm} .{ }^{2}$ If the size exceeds $4 \mathrm{~cm}$ it is "aneurysmal" which may be true of false.

3. PAA could be congenital due to Eisenmenger' syndrome, Pulmonary valve stenosis and absent pulmonary valve syndrome. Connective tissue disorders (Marfan's syndrome, alpha-1 antitrypsin deficiency and Ehlers-Danlos syndrome) and autoimmune disorders (Behcet's disease and Hughes-Stovin syndrome). ${ }^{3}$

4. Acquired causes include PAH, auto-immune disease (vasculitis), trauma infections, malignancy and idiopathic.

5. For intervention no consensus of opinion is available. However expert opinion recommends it when the patient becomes symptomatic or pulmonary artery diameter exceeds $5 \mathrm{~cm}$ to 6 $\mathrm{cm}$. 


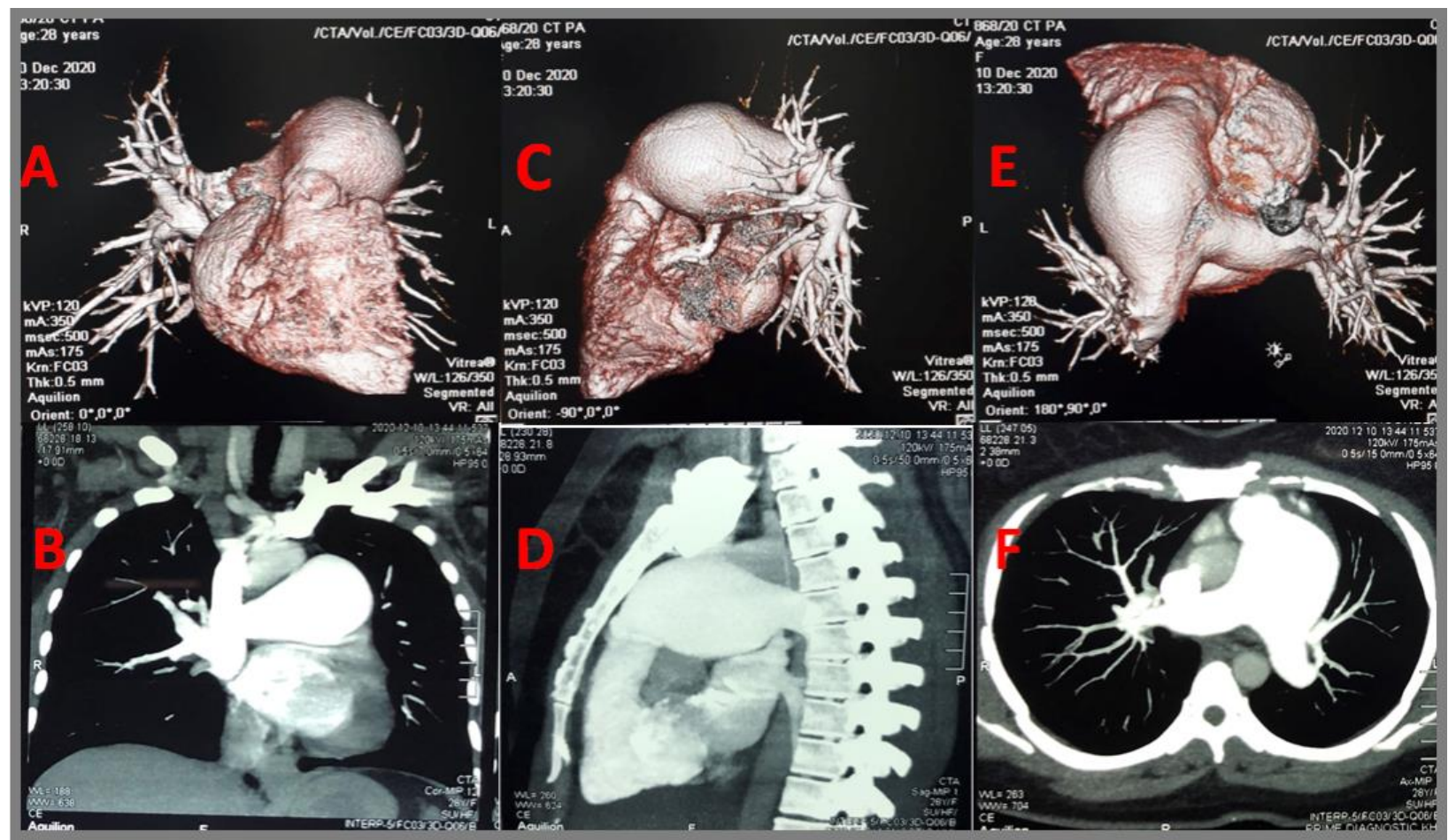

Figure 1: Pulmonary artery aneurysm-idiopathic. Panel A and B- Coronal, Panel C and D- Sagittal, and Panel $E$ and $F$ Axial cuts of CT angiogram

\section{QUESTIONS WITH ANSWERS}

- Question 1: Is there any difference in the measurement of PA size by echocardiography and CT?

- Question 2: What is the usual site of dissection in PAA?

- Question 3: In Pulmonary arterial tree what is the most frequent site of aneurysm?

- Question 4: Some cases of pulmonary artery aneurysms can be managed medically- Y/N?

- Question 5: The technique of choice for diagnosing PA aneurysm is pulmonary angiography or CT angiogram?

\section{Answers}

- Question 1: Yes

- Question 2: Main PA

- Question 3: Right lobar artery

- Question 4: Yes

- Question 5: CT angiogram

\section{REFERENCES}

1. Deterling RA Jr and Clagett OT. Aneurysm of the pulmonary artery; review of the literature and report of a case. Am Heart J. 1947;34:471-99.

2. Truong QA, Massaro JM, Rogers IS, Mahabadi AA, Kriegel MF, Fox CS. Reference values for normal pulmonary artery dimensions by noncontrast cardiac computed tomography: The Framingham Heart Study. Circ Cardiovasc Imaging 2012;5:14754.

3. Agarwal S, Chowdhury UK, Saxena A, Ray R, Sharma S, Airan B. Isolated idiopathic pulmonary artery aneurysm. Asian Cardiovasc Thorac Ann. 2002;10(2):167-9.

Citation: Hameed I. Pulmonary Artery Aneurysm- Idiopathic. Pak Heart J. 2021;54(02):203-204. DOI: https://doi.org/10.47144/phj.v54i2.2101

\section{Address for Correspondence:}

Dr. Imran Hameed, Anklesaria Nursing Home, Aga Khan III road garden, Karachi, Pakistan.

Email: imranhameed61@ hotmail.com 